\title{
Clinical Evaluation of In-Ceram Crowns Fabricated Using GN-I System: Preliminary Results after 24-39 Months of Use
}

\author{
Yuji Kokubo, DDS, PhD, ${ }^{a, b}$ Mitsuyoshi Tsumita, DDS, PhD, ${ }^{a, b}$ Yuki Nagayama, DDS, ${ }^{b}$ \\ Satoe Sakurai, DDS, ${ }^{b}$ Samito Yamazaki, DDS, ${ }^{a}$ Makoto Kuga, CDT, ${ }^{c}$ \\ Chikahiro Ohkubo, DDS, PhD, ${ }^{\mathrm{b}, \mathrm{d}}$ and Shunji Fukushima, DDS, $\mathrm{PhD}^{\mathrm{a}}$ \\ ${ }^{a}$ Department of Fixed Prosthodontics, Tsurumi University School of Dental Medicine, Yokohama, Japan \\ ${ }^{\mathrm{b}}$ Division of Oral and Maxillofacial Implantology, Tsurumi University School of Dental Medicine, Yokohama, Japan \\ ${ }^{c}$ Core Dental Laboratory Yokohama, Yokohama, Japan \\ d Department of Removable Prosthodontics, Tsurumi University School of Dental Medicine, Yokohama, Japan
}

\section{Clinical significance}

There are no in vivo studies on the clinical performance of In-Ceram crowns fabricated using the GN-I system. In this study, the In-Ceram crowns functioned satisfactorily over a mean evaluation period of 28.7 months.

\begin{abstract}
Purpose: This study prospectively evaluated the clinical performance of CAD/CAM-generated In-Ceram alumina core crowns.

Methods: The GN-I system was used to fabricate the 101 In-Ceram crowns with aluminum copings placed in 39 patients. Using a modified quality assessment system developed by the California Dental Association (CDA), the crowns were evaluated at baseline and at all follow-up examinations.

Results: The mean service time of the crowns was 28.7 months. Six crowns fractured or were removed; a maxillary first molar crown and a mandibular second premolar crown fractured after 17 months and 22 months, respectively. Others were removed due to esthetic complications, endodontic therapy, root fracture, and so on. A small chip was detected in a mandibular canine crown after functioning for 6 months. After 39 months, the cumulative survival rate of the crowns was $93.9 \%$. According to the modified CDA criteria, most crowns were rated as "satisfactory" during the observation period.

Conclusion: Despite the 2 fractures, In-Ceram Alumina crowns with copings fabricated using CAD/CAM (GN-I system) showed excellent results during the observation period.
\end{abstract}

\section{Corresponding to: Dr Yuji Kokubo}

Department of Fixed Prosthodontics, Tsurumi University

School of Dental Medicine

2-1-3 Tsurumi Tsurumi-ku, Yokohama 230-8501, Japan

Tel: +81-45-581-1001, Fax: +81-45-573-9599

E-mail:kokubo-y@tsurumi-u.ac.jp

Received on January 25, 2007 / Accepted on July 4, 2007
Key words: CAD/CAM, In-Ceram crowns, GN-I system, survival rate

\section{Introduction}

All-ceramic crowns are a popular option for esthetic restoration of carious teeth for not only the anterior but also the posterior region. The InCeram system was first introduced in $1990^{1}$ and has been used successfully as an alternative to conventional porcelain-fused-to-metal crowns. ${ }^{2-11}$

Originally, a slip-cast aluminum oxide ceramic was used in In-Ceram crowns. Recently, many computer-aided design/computer-aided manufacturing (CAD/CAM) systems have been developed for use in dentistry. The first CAD/CAM-designed restorations (8 CEREC inlays) were placed in vivo in $1986 .{ }^{12}$ In 1997 , the introduction of the crown software and the Cerec 2 system allowed the design and machining of all-ceramic copings. ${ }^{13,14}$ Since then, manufacturers have developed CAD/CAM systems to fabricate titanium, composite, aluminum oxide, and zirconium oxide crowns or copings that fit more precisely on the abutments. It is believed that the ceramic copings fabricated with these CAD/CAM systems are stronger than laboratory-processed copings and that industrially prefabricated material has greater flexural strength than the conventional In-Ceram material. ${ }^{15}$ Because commercially fabricated blocks (Vita Zahnfabrik, Bad Säckingen, Germany) have minimal flaws and cracks, their fracture strength varies within a small range when compared with that of conventional InCeram material. With the use of such commercially made materials, clinical problems such as fracture of copings are less likely to occur. ${ }^{15,16}$ 
Furthermore, densely sintered aluminum and zirconium oxide ceramic blocks (In-Ceram 2000 AL Cubes and In-Ceram 2000 YZ Cubes; Vita Zahnfabrik) that are now available can be processed using CAD/CAM technology. ${ }^{17}$

The GN-I system (GC Corp., Tokyo, Japan) was introduced for clinical use in $1999 .{ }^{18}$ Using milling burs with 5 different diameters, this system can produce In-Ceram copings from alumina blocks. The advantages of this system are as follows: (1) the copings have greater mechanical strength ${ }^{19,20}$; (2) a refractory model is not required; (3) production is not labor intensive; (4) identical copings can be produced easily; (5) copings of uniform thickness can be produced easily; (6) there is less variation in strength ${ }^{16}$; (7) the copings can be designed easily; and (8) the marginal gaps are clinically acceptable. ${ }^{21}$

The purpose of this clinical study was to examine the clinical performance of In-Ceram crowns manufactured using the GN-I system over a 2-year period by using a modified California Dental Association (CDA) system.

\section{Materials and methods}

Between July 2003 and October 2004, 101 InCeram crowns with copings fabricated using the GN-I system were fixed in patients at the Tsurumi University Dental Hospital. The patients were selected according to the following criteria: (1) not a heavy bruxer or clencher, (2) less than 70 years of age, (3) understood the purpose of the study, (4) agreed to undergo follow-up examinations up to 5 years, (5) had low caries activity, and (6) was periodontally healthy. Of the $54 \mathrm{pa}^{-}$ tients recruited, 39 patients met the inclusion criteria and were selected; informed consent was obtained from these patients.

The 39 patients included 9 males and $30 \mathrm{fe}^{-}$ males; their mean age was 50.9 years. The patients received an average of $2.6 \mathrm{In}$-Ceram crowns (range, 1-9 crowns). This study was reviewed and approved by the ethics committee of Tsurumi University (No. 109). The distribution of restorations by tooth is listed in Figure 1. Maxillary and mandibular anterior teeth were most frequently restored. Of the restored teeth, 39 teeth were vital, and 62 teeth were non-vital.

Three dentists treated the patients, and all InCeram crowns used in this study were fabricated at the same commercial laboratory (Core Dental

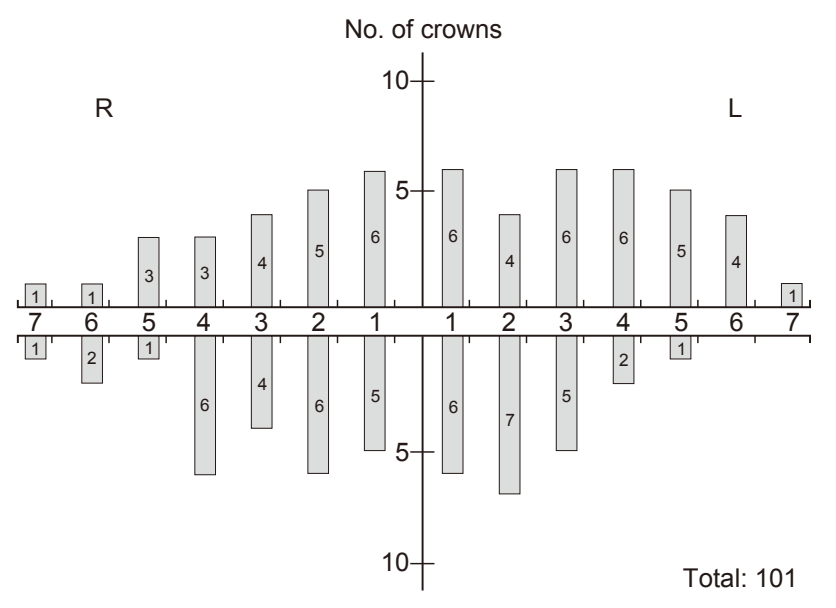

Fig. 1 Baseline distribution by position of In-Ceram crowns fabricated using GN-I.

Laboratory, Yokohama, Japan). All the teeth were prepared with chamfer margins using special preparation burs (All-Ceramic Preparation Kit; Shofu Inc., Kyoto, Japan) according to the manufacturer's protocol, i.e., minimum occlusal reduction of $1.5 \mathrm{~mm}$ and chamfer width of $0.8 \mathrm{~mm}$. $\mathrm{Im}^{-}$ pressions were made using a vinyl polysiloxane impression material (Exafine; GC Corp.). The working models were then fabricated with a Type IV stone (GN-I CAD stone; GC Corp.). All the dies were scanned with a non-contact laser sensor in the measuring machine. Then, the coping was designed on the computer monitor; the cement space $(50 \mu \mathrm{m})$, starting point of the cement space $(1.5 \mathrm{~mm}$; the distance from the margin along the axial wall; there are no cement space in this area), and coping thickness $(0.5 \mathrm{~mm})$ were determined using the software program. Finally, prefabricated In-Ceram aluminum oxide blanks (Vita Zahnfabrik) were fixed on a standardized support table and milled using burs with 5 different diameters. The internal surfaces of the copings were checked using silicone materials (Fit Checker; GC Corp.). Points making tight contact were removed. The margins of the copings were adjusted using Alumina Optimizer (Vita Zahnfabrik). Glass was then infiltrated into each coping in the furnace (Inceramat; Vita Zahnfabrik). Excess glass was removed using a bur and airborne particle abrasion with $50-\mu \mathrm{m}$ alumina particles at a pressure of 2 bars. All crowns were fired with the same veneering porcelain (Vitadur Alpha; Vita Zahnfabrik) for each coping.

Forty-seven crowns were cemented using Panavia F 2.0 (Kuraray Medical, Tokyo, Japan), and 
Table 1 Criteria of modified CDA rating.

\begin{tabular}{|c|c|}
\hline \multicolumn{2}{|l|}{ Marginal integrity } \\
\hline Excellent: & $\begin{array}{l}\text { No visible evidence of a crevice along the margin into which the explorer will penetrate. No } \\
\text { discoloration of the margin between the restoration and the tooth structure. }\end{array}$ \\
\hline Acceptable: & $\begin{array}{l}\text { Visible evidence of slight marginal discrepancy with no evidence of decay; repair can be done or } \\
\text { is unnecessary. Discoloration of the margin between the restoration and the tooth structure. }\end{array}$ \\
\hline Correction: & $\begin{array}{l}\text { Faulty margins that cannot be properly repaired. Penetrating discoloration along the margin } \\
\text { of restoration in the pulpal direction. Retained excess cement. }\end{array}$ \\
\hline Replacement: & $\begin{array}{l}\text { Mobile restoration. Fractured restoration. Caries continuous with the margin of restoration. } \\
\text { Tooth structure fractured. }\end{array}$ \\
\hline \multicolumn{2}{|l|}{ Color } \\
\hline Excellent: & No mismatch in color shade and/or translucency between restorations and adjacent teeth. \\
\hline Acceptable: & Slight mismatch of shade between restorations and adjacent teeth. \\
\hline Correction: & $\begin{array}{l}\text { Mismatch between restorations and adjacent tooth or teeth outside the normal range of color, } \\
\text { shade, and/or translucency. }\end{array}$ \\
\hline Replacement: & Shade in gross disharmony with adjacent teeth. \\
\hline \multicolumn{2}{|l|}{ Surface } \\
\hline Excellent: & Restoration surface is smooth. No irritation of adjacent tissue. \\
\hline Acceptable: & Restoration surface is slightly rough or pitted but can be polished. \\
\hline Correction: & Gross surface irregularity not related to anatomy and not subject to correction \\
\hline Replacement: & Surface is fractured. Porosities in the crown material. \\
\hline \multicolumn{2}{|l|}{ Anatomic form } \\
\hline Excellent: & $\begin{array}{l}\text { Restoration contour in functional harmony with the adjacent teeth, and soft tissues within } \\
\text { good individual anatomic form. }\end{array}$ \\
\hline Acceptable: & $\begin{array}{l}\text { Restoration slightly overcontoured. Restoration slightly undercontoured. Occlusion is not com- } \\
\text { pletely functional. Marginal ridges slightly undercontoured. Contact slightly open. Facial flat- } \\
\text { tening is present. Lingual flattening is present. }\end{array}$ \\
\hline Correction: & $\begin{array}{l}\text { Restorations grossly undercontoured. Restorations slightly overcontoured. Occlusion is affect- } \\
\text { ed. Contact is faulty. Marginal overhang is present. }\end{array}$ \\
\hline Replacement: & $\begin{array}{l}\text { Traumatic occlusion. Gross underocclusion. Restoration causes unremitting pain in the tooth } \\
\text { or adjacent tissue. Damage to tooth, soft tissue, or supporting bone. }\end{array}$ \\
\hline
\end{tabular}

54 crowns were cemented using GC Fuji Luting S (GC Corp.).

The examinations were scheduled at the time of cementation (baseline) and every year thereafter for 5 years. Each examination was performed by 2 authors using the modified $\mathrm{CDA}^{22}$ quality evaluation system to assess the marginal integrity, surface, color, and anatomic form. The examiners were different from the dentists who fitted each crown. The items in the modified CDA system were rated as one of the following: (1) excellent or acceptable and (2) correction or replacement (Table 1). The 2 investigators examined all restorations independently. In case of disagreement between them, the investigators reexamined the crowns, and the final score was determined by a joint decision following discussions. Before starting the examinations, the investigators were calibrated using several typical clinical situations. During the examination, the investigators also recorded the condition of the soft tissue surrounding the restored teeth and control teeth, including the amount of dental plaque ${ }^{23}$ and gingival bleeding. ${ }^{24}$ Any fracture, chipping, cracking, and occurrence of marginal caries in each crown were also recorded.

The cumulative survival rate was calculated (SPSS Base 10.0; SPSS Inc., Chicago, IL, USA) using Kaplan-Meier analysis (cumulative method) ${ }^{25}$ Crowns lost to follow-up were censored, and all fractures or chipping noticed by patients was reported at the time of fracture after baseline. Fractured In-Ceram crowns requiring replacement were considered as failures.

The average plaque index (PI) scores and average scores of bleeding during probing of the InCeram crowns were compared with those of control teeth during each follow-up using Student's $t$-test. 


\section{Results}

The cumulative survival rates of the In-Ceram crowns during the observation period are shown in Figure 2. All crowns, except those excluded for various reasons (fracture, removal, or lost to follow-up), were followed-up for up to 39 months and at least 24 months of function.

At the first-year follow-up examination, $1 \mathrm{pa}^{-}$ tient had migrated away from the study area and was excluded.

One mandibular molar crown was removed and remade after 1 month of function owing to esthetic complaints from the patient. A small chip was detected in a mandibular canine crown after 6 months of function; it was polished and thereafter functioned without any problems. The cumulative survival rate of the crowns after 1 year was $99.0 \%$.

No patients were lost to follow-up at the second-year follow-up examination. During this period, a maxillary first molar crown fractured from the coping at 17 months and was removed; this incident occurred when the patient was eating dry fruits. At 19 months, a maxillary first premolar was extracted with the crown because of root fracture. A mandibular second premolar crown was removed due to fracture of the coping at 22 months. At 23 months, a maxillary second premolar was removed for endodontic therapy. The cumulative survival rate after 2 years was 95.0\%.

No patients were lost to follow-up at the thirdyear follow-up examination. However, after 25 months, a maxillary canine crown was removed because the tooth had been used as the abutment tooth of a fixed partial denture since the adjacent tooth was lost. The cumulative survival rate after 3 years was $93.9 \%$.

According to the modified CDA criteria, all examined crowns were rated as satisfactory with regard to marginal integrity, color, surface, and anatomic form at all follow-ups, except for 1 chipped crown during the observation period (Table 2).

The average PI scores (SDs) of the In-Ceram crowns and the control teeth at baseline and $1^{-}$, 2 -, and 3-year evaluations were $0.059(0.238)$, 0.150 (0.359), $0.223(0.419)$, and 0.143 (0.363); and $0.040(0.196), 0.190(0.394), 0.191$ (0.396), and $0.143(0.363)$, respectively. There were no significant differences in the average PI scores

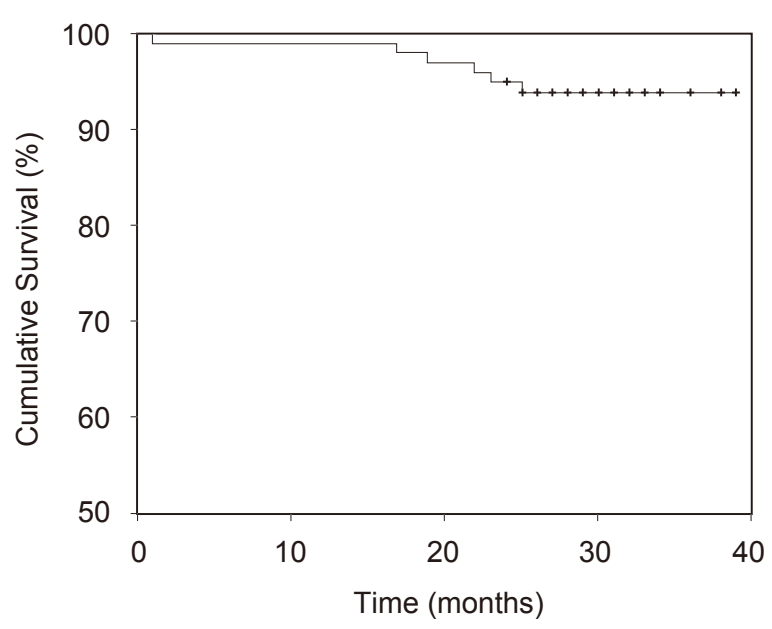

Fig. 2 Cumulative survival rates of In-Ceram crowns as determined by Kaplan-Meier analysis.

Table 2 Quality of In-Ceram crowns at baseline and at 1-, 2-, and 3-year follow-ups according to the modified CDA (\%).

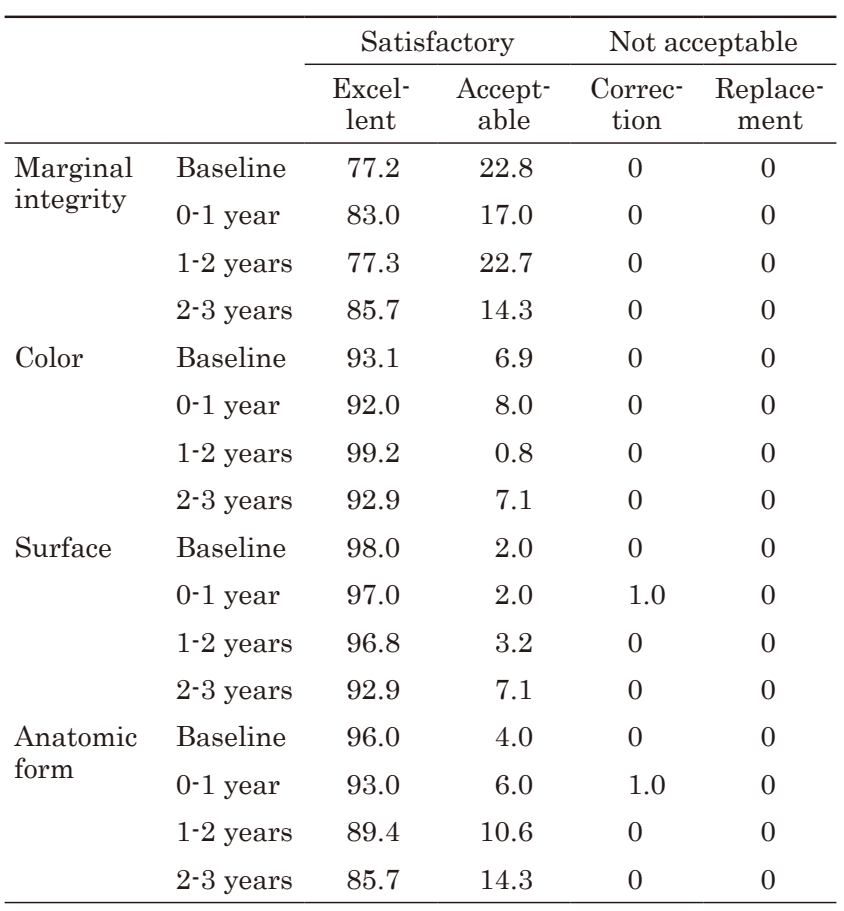

between In-Ceram crowns and control teeth at each follow-up examination.

The average scores (SDs) for bleeding during probing of the In-Ceram crowns and control teeth at baseline and 1-, 2-, and 3-year evaluations were $0.050(0.218), 0.090$ (0.288), 0.181 (0.387), and $0.071(0.267)$; and $0.010(0.100)$, $0.020(0.141), 0.085(0.281)$, and $0.143(0.363), \mathrm{re}^{-}$ spectively. A significant difference in the average scores for bleeding during probing was observed between the In-Ceram crowns and control teeth 
at the first follow-up examination.

No secondary caries were clinically detected during this period.

\section{Discussion}

During the observation period, the mean service time was 28.7 months, with a range of 24-39 months; during this period, 2 crowns fractured, and 4 crowns were removed for other reasons (esthetic complaint, root fracture, endodontic therapy, and abutment tooth for a fixed partial denture). The cumulative survival rate after 39 months was $93.9 \%$, which is a promising preliminary result. Fractures were observed only in the molar and premolar regions. In other studies, most of the clinical data were gathered for conventional In-Ceram crowns with alumina copings. Scotti et $\mathrm{al}^{4}$ showed that out of $63 \mathrm{In}^{-}$ Ceram Alumina crowns followed-up for a mean service time of 37.6 months, 1 premolar crown had to be replaced because of fracture. In their clinical study, McLaren and White ${ }^{6}$ showed that the failure of In-Ceram crowns tended to be more common for molar and premolar crowns than for anterior crowns. Haselton et $\mathrm{al}^{7}$ encountered 1 molar crown failure and reported the same tendency. Furthermore, Scherrer et $\mathrm{al}^{8}$ reported a higher fracture rate for posterior teeth than for anterior teeth. Segal ${ }^{9}$ found a higher survival rate in anterior crowns than in posterior crowns. Since there is no comparable for GN-I In-Ceram copings, further research is needed to confirm whether posterior GN-I In-Ceram crowns have a higher failure rate.

The clinical success of all-ceramic restorations has been disappointing for posterior crowns. ${ }^{26}$ Compared to other all-ceramic crowns, Procera crowns have been reported to have survival rates of $97.7 \%$ and $93.5 \%$ after 5 and 10 years, respectively, ${ }^{27}$ indicating a good prognosis for posterior teeth. In addition, Procera All Ceram crowns had a failure rate of $3 \%$ and showed encouraging results when used for replacing anterior and posterior teeth during a 5 -year period. ${ }^{28}$ Kokubo et $\mathrm{al}^{29}$ reported a survival rate of $93.2 \%$ after a 3-year follow-up, and fractures were seen only in the premolar and molar regions. The all-ceramic systems tend to fracture in the posterior region.

In contrast to other CAD/CAM systems using In-Ceram Alumina blocks (Vitablock In-Ceram Alumina, Vita Zahnfabrik), the Celay system copy-mills an industrially sintered blank; therefore, the time needed to fabricate In-Ceram copings is greatly reduced. ${ }^{15,20}$ Rinke et $\mathrm{al}^{15}$ found that the milling procedure has no effect on the mechanical properties of alumina blanks. Furthermore, the greater fracture resistance of copy-milled anterior crowns fabricated from the glass-infiltrated Celay alumina blanks provides a slightly higher flexural strength when compared with that of crowns fabricated from conventional alumina core materials. ${ }^{20}$ There is less variation in the fracture resistance of copymilled units (Celay system, Mikrona Technology AG, Spreitenbach, Switzerland) when compared with conventionally fabricated units. ${ }^{20}$ The Celay system produces aluminum copings by copymilling them from industrially sintered aluminum oxide blanks. On the other hand, the GN-I system scans the die of a working cast directly; therefore, it is possible that there will be some differences in the marginal and internal gaps between the 2 systems. ${ }^{15}$ Regarding the GN-I system used in this study, the die of each tooth was first scanned using a laser beam. Then, the margin was checked on the computer monitor, after which the coping was milled from the prefabricated In-Ceram Alumina block. However, it is possible to make changes in size because this system requires a conventional impression and a working model, whereas CEREC inLab, for example, does not require a working model. In addition, Bindl and Mörmann ${ }^{10}$ evaluated the clinical performance of CAD/CAM-generated (Cerec 2 CAD/CAM system; Siemens AG, Munich, Germany) In-Ceram Alumina coping crowns; after a mean service time of 39 months, they reported a survival rate of $92 \%$, which was similar to the results of clinical studies on conventional In-Ceram crowns. ${ }^{6,7}$

Some important factors affect the long-term clinical results of In-Ceram crowns milled using a CAD/CAM system. Porosity is important for determining resistance to stress ${ }^{30,31}$ since pores are potential sites for crack initiation. Conventionally fabricated In-Ceram crowns are infiltrated with molten glass, providing a homogenous core consisting of fine particles in a vitreous matrix. Industrially manufactured blocks have less porosity than conventional In-Ceram crown copings. The mechanical strength of core material fabricated using CAD/CAM and sintered glass is approximately $525 \mathrm{MPa}$, which is stronger than the strength of conventionally fabricated core 
material. ${ }^{19}$ In addition, even thickness of core material is important because it influences deformation when the porcelain is fired; small variations in thickness can affect the restorations considerably. ${ }^{32}$ Complete breakage of cracked allceramic crowns can occur clinically after 17 to 22 months because of the stress occurring during mastication. The potential for cracks is also present under laboratory conditions. Early fractures, which may be related to processing defects, were not observed in the present study. Late fractures may be related to fatigue effects. This means that the copings fabricated using the GN-I system may have fewer processing defects than conventional In-Ceram crowns that had early fractures. ${ }^{11}$ Kelly $^{33}$ also reported that the structural durability of all-ceramic crowns is affected by the type of ceramic materials, luting system, and occlusal load.

It is less likely that clinical problems such as fracture of copings will occur. ${ }^{15,20,34}$ In this study, the failure rate due to crown fractures was approximately $2 \%$ after a mean clinical service time of 28.7 months. Although 4 crowns were removed, the failure could not be attributed to a failure of the crown itself.

The clinical reliability of all-ceramic restorations mainly depends on marginal integrity, mechanical strength of core material, and longterm results. The clinical marginal integrity of the CAD/CAM-generated In-Ceram crowns used in this study is promising, ${ }^{21}$ and the mechanical strength of CAD/CAM-generated copings is high. ${ }^{19}$ However, questions have been raised regarding the long-term clinical results. CAD/ CAM-generated copings will be altered based on casting and hand-made techniques. The manufacturer recommends a chamfer margin because it is difficult to mill a complicated curved surface, including both concave and convex areas. In this study, all teeth were prepared using burs of the same size, and all concave areas were adjusted before impressions were taken.

The advantage of fabricating copings using the GN-I system is the shorter processing time. Many fabrication steps are avoided with the GN-I system because the CAM system machines the blocks of presintered In-Ceram aluminum. According to information provided by the dental technician who fabricated these In-Ceram crowns, approximately 7 hours will be saved by using the GN-I system when compared with the conventional slip-casting technique.
The plaque and bleeding scores of the $\mathrm{In}^{-} \mathrm{Ce}^{-}$ ram crowns were not lower than those of the control teeth, as in other studies. ${ }^{10,19,35}$ In the present study, all crowns were luted with adhesive cement. The manufacturer states that any variety of cement may be used while luting these crowns. Prior to starting this study, we did not place a restriction on the type of cement to be used. How ${ }^{-}$ ever, only 2 varieties of adhesive cements were used. No caries were detected during the short observation period, as in other studies in which the crowns were luted with zinc phosphate cement. ${ }^{5}$

In this preliminary study of up to 39 months, no failure of In-Ceram crowns was attributed to caries or periodontal problems. This may be the result of good oral hygiene in patients, indicated by very low PI and gingival index (GI) values as compared to those in other studies. ${ }^{10,19,34}$ Only at the 1-year follow-up examination, the GI values of In-Ceram crowns were significantly higher than those of control teeth; this is indicative of increased risk of gingival inflammation around crowned teeth. Since the observation period was very short, a follow-up period of at least 5 years is needed to provide definite and conclusive evidence of the effectiveness of GN-I In-Ceram crowns.

\section{Conclusion}

Within the limitations of this clinical study, the aluminum copings, which were fabricated by CAD/CAM (GN-I system), showed excellent results during the mean service time of 28.7 months. The cumulative survival rate of the copings after 39 months was $93.9 \%$.

\section{References}

1. Claus H. Vita In-Ceram, ein neues Verfahren zur Herstellung oxidkeramischer Gerüste für Kronen und Brücken. Quintessenz Zhantech 16: 35-46, 1990.

2. Pröbster L. Survival rate of In-Ceram restorations. Int J Prosthodont 6: 259-263, 1993.

3. Pang SE. A report of anterior In-Ceram restorations. Ann Acad Med Singapore 24: 33-37, 1995.

4. Scotti R, Catapano S, D'Elia A. A clinical evaluation of In-Ceram crowns. Int J Prosthodont 8: 320-323, 1995.

5. Pröbster L. Four year clinical study of glass-infil- 
trated, sintered alumina crowns. J Oral Rehabil 23: 147-151, 1996.

6. McLaren EA, White SN. Survival of In-Ceram crowns in a private practice: a prospective clinical trial. J Prosthet Dent 83: 216-222, 2000.

7. Haselton DR, Diaz-Amold AM, Hillis SL. Clinical assessment of high-strength all-ceramic crowns. J Prosthet Dent 83: 396-401, 2000.

8. Scherrer SS, De Rijk WG, Wiskott HW et al. Incidence of fractures and lifetime predictions of allceramic crown systems using censored data. Am J Dent 14: 72-80, 2001.

9. Segal BS. Retrospective assessment of 546 allceramic anterior and posterior crowns in a general practice. J Prosthet Dent 85: 544-550, 2001.

10. Bindl A, Mörmann WH. An up to 5-year clinical evaluation of posterior In-Ceram CAD/CAM core crowns. Int J Prosthodont 15: 451-456, 2002.

11. Kokubo Y, Tsubota Y, Fukagawa N et al. Clinical evaluation of In-Ceram crowns. Prosthodont Res Pract 5: 86-90, 2006.

12. Eidenbenz S. Das Kopierschleifen keramischer Formkorper (Med Diss thesis). Zürich 32-49, 1992.

13. Bindl A, Mörmann WH. Klinische und technische Aspekte der CEREC In-Ceram Krone. Die Quintessenz 47: 775-972, 1996.

14. Bindl A, Mörmann WH. Chairside-ComputerKronen Verfahrenzeit und klinische Qualität. Acta Med Dent Helv 2: 293-300, 1997.

15. Rinke S, Hüls A, Jahn L. Marginal accuracy and fracture strength of conventional and copy-milled all-ceramic crowns. Int J Prosthodont 8: 303-310, 1995.

16. Bindl A, Mörmann WH. Survival rate of monoceramic and ceramic-core CAD/CAM-generated anterior crowns over 2-5 years. Eur J Oral Sci 112: 197-204, 2004.

17. Wassermann A, Kaiser M, Strub JR. Clinical longterm results of VITA In-Ceram Classic crowns and fixed partial dentures: A systematic literature review. Int J Prosthodont 19: 355-363, 2006.

18. Hikita K, Uchiyama Y, Iiyama K et al. Function and clinical application of dental CAD/CAM "GN-I". Int J Comput Dent 5: 11-23, 2002.

19. Fasbinder D. Utilizing lab-based CAD/CAM technology for metal-free ceramic restorations. Dent Today 22: 100-102, 104-105, 2003.

20. Hwang JW, Yang JH. Fracture strength of copymilled and conventional In-Ceram crowns. J Oral Rehabil 28: 678-683, 2001.
21. Kokubo Y, Nagayama Y, Tsumita M et al. Clinical marginal and internal gaps of In-Ceram crowns fabricated using the GN-I system. J Oral Rehabil 32: 753-758, 2005.

22. California Dental Association. Quality Evaluation for Dental Care. Guidelines for Assessment of Clinical Quality and Professional Performance. Los Angeles: California Dental Association, 1977.

23. Silness J, Löee H. Periodontal disease in pregnancy. II. Correlation between oral hygiene and periodontal condition. Acta Odontol Scand 22: 121-135, 1964.

24. Saxer UP, Mühlemann HR. Motivation and education. Schweiz Monatsschr Zahnneilkd 85: 905-919, 1975.

25. Kaplan EL, Meier P. Nonparametric estimation from incomplete observations. J Am Stat Assoc 53: 457-465, 1958.

26. Moffa JP, Lugassy AA, Ellison JA. Clinical evaluation of castable ceramic material. Three-year study \{IADR abstract 43\}. J Dent Res 67(special issue): $118,1988$.

27. Ödman P, Andersson B. Procera AllCeram crowns followed for 5 to 10.5 years: a prospective clinical study. Int J Prosthodont 14: 504-509, 2001.

28. Oden A, Andersson M, Krystek-Ondracek I et al. Five-year clinical evaluation of Procera AllCeram crowns. J Prosthet Dent 80: 450-456, 1998.

29. Kokubo Y, Tsumita M, Nagayama Y et al. Prospective clinical study of Procera AllCeram crowns: 2-3 year preliminary results. Prosthodont Res Pract 5: 80-85, 2006.

30. McLean JW. The science and art of dental ceramics, Vol 1. 55-63, Chicago: Quintessence, 1975.

31. Munoz CA, Goodacre CJ, Moore BK et al. A comparative study of the strength of aluminous porcelain jacket crowns constructed with the conventional and twin foil technique. J Prosthet Dent 48: 271-281, 1982.

32. Riley EJ. Ceramo-metal restoration. State of the science. Dent Clin North Am 21: 669-682,1997.

33. Kelly JR. Clinically relevant approach to failure testing of all-ceramic restorations. J Prosthet Dent 81: 652-661, 1999.

34. Tinschert J, Zwez D, Marx R et al. Structural reliability of alumina-, feldspar-, leucite-, mica- and zirconia-based ceramics. J Dent 28: 529-535, 2000.

35. Chan C, Weber H. Plaque retention on teeth restored with full-ceramic crowns: a comparative study. J Prosthet Dent 56: 666-671, 1986. 